\title{
Assessing the Built Environment of Neighbourhood in the Winter City from the Perspective of Pupils' Commuting Safety
}

Hong Leng, School of Architecture, Harbin Institute of Technology, Key Laboratory of Cold Region Urban and Rural Human Settlement Environment Science and Technology, Ministry of Industry and Information Technology, China

Chunyu Zou, School of Architecture, Harbin Institute of Technology, Key Laboratory of Cold Region Urban and Rural Human Settlement Environment Science and Technology, Ministry of Industry and Information Technology, China

Huimin Zhao, School of Architecture, Harbin Institute of Technology, Key Laboratory of Cold Region Urban and Rural Human Settlement Environment Science and Technology, Ministry of Industry and Information Technology, China

\begin{abstract}
Safety commuting environment can promote children's walking and cycling, thus reducing the risk of obesity and other diseases. Most of the existing studies on children's safety focus on open space, but pay little attention to children's commuting environment. Moreover, few studies pay attention to the differences between open blocks and gated communities in winter city. Taking Harbin, a winter city in China, as an example, this study uses the optimized IPA method to explore the built environment factors affecting pupils' commuting safety from three aspects: environment design, social management and road traffic. The results show that the influencing factors of road traffic have the highest impact on pupils' commuting safety. In addition, the occupation management in social management also has a great impact. In terms of satisfaction, the satisfaction with gated communities is generally higher than that with open blocks, but the satisfaction of open block is higher in neighbourhood relationship and street thermal environment. By coupling the importance and satisfaction of influencing factors, it is found that safety guardrail, signal identification, occupation management are in urgent need of renovation.
\end{abstract}

\section{Keywords}

Commuting Safety, Pupils, Winter City, IPA, Gated communities, Open blocks

\section{Introduction}

In China, it is an urgent problem to be solved for urban transportation, urban planning and management to create a good commuting environment for children ${ }^{[1]}$. School travel is a potential opportunity to integrate physical activities such as walking and cycling into children's daily life ${ }^{[2]}$. Active commuting is associated with multiple health benefits, such as weight levels ${ }^{[3]}$, physical health ${ }^{[4]}$, and mental health ${ }^{[5]}$. At the same time, due to the significant reduction in carbon dioxide emissions and traffic congestion, active commuting can also produce environmental benefits, as well as social benefits brought by the improvement of neighbourhood relationships ${ }^{[6]}$. However, in recent years, the proportion of children walking and cycling to school (also known as "active commuting") has decreased sharply ${ }^{[7]}$. The increase in the car-oriented built environment, the decrease in attention to sidewalk infrastructure, 
and the parents' concern for children's solitary travel safety limit children's active commuting ${ }^{[8-10]}$.

Existing studies have shown that the built environment is related to children's active commuting. Safe commuting environment can promote children to walk to school. Besides the basic transportation function ${ }^{[11]}$, street is also an important space for children to perceive the external environment and have communication activity ${ }^{[12]}$. Many elements of streets can help stimulate children's creativity, imagination and learning ability, and promote children's communicative behaviours ${ }^{[13]}$.

Most of the existing studies focus on children's activities in school and leisure time, but ignore the school travel behaviour of pupils. Moreover, few studies focus on the differences between the commuting environment of gated communities and open blocks in winter city ${ }^{[14]}$. Taking Fuhua Primary School and Fuhua Science and Technology Park Primary School of Harbin as examples, this paper explores the characteristics of pupils' school travel behaviour and the influencing factors of pupils' commuting safety in different types of neighbourhood. And using optimized IPA to sort the influencing factors, the research obtains the influencing factors which need to be renewed urgently, and puts forward suggestions appropriately.

\section{Review}

The related research on children's school travel behaviour started in the field of public health abroad in the 1980s, which proposed that the improvement of built environment could promote children's active commuting, so as to reduce the obesity rate ${ }^{[15]}$. After that, the field of urban planning began to study the characteristics of the built environment influencing children's school travel, which attracted more attention of scholars. McMillan was the first to establish a framework for the relationship between built environment and school travel mode ${ }^{[16]}$. Other foreign scholars have obtained the relationship between built environment ${ }^{[17]}$, land-use pattern ${ }^{[18]}$ and children's school travel behaviour through data analysis. But on the whole, the scope of existing researches is large, and there are few relevant achievements on children's walking environment at the fine level. In recent years, domestic scholars have begun to carry out research on children's school travel. For example, Wu Fengwen et al. took the characteristics of children's walking and cycling commuting as the entry point to construct index system to evaluate the safety of the commuting environment ${ }^{[12]}$; Yang Shen et al. studied the safety relationship between children's school travel path and community spatial structure [19]; Wang Xia et al. focused on the spatialtemporal feature and restriction mechanism of pupil' school travel ${ }^{[20]}$. In conclusion, the current research on children's school travel mainly focuses on the objective measurement of built environment, but lacks the measurement of subjective perception dimension. Most of the empirical studies on school travel are based on the community scale, and lack of comparative study on the impact of the built environment of open blocks and gated communities on children's school travel behaviour. At the level of guiding implementation, the current research achievements are of little help for the fine guidance of commuting environment design. The purpose of this paper is to use the subjective perception method to explore the built environment elements that affect children's school travel behaviour in gated communities and open blocks, and provide guidance for the commuting environment optimization, so as to promote children's active commuting.

\section{Material}

\subsection{Research Object}

Built environment is closely related to school travel. In China, urban primary schools are mostly built beside communities, and neighbourhood is the main commuting environment for primary school 
students. At present, China's residential areas are mainly divided into gated communities and open blocks, which have great differences in construction time, location, residents and built environment characteristics. The built environment in Harbin is characterized by circle layers, which can be roughly divided into two categories: the old urban area (within the Second Ring Road) are mainly old open blocks which is characterized by high building density and low storey number, relatively low development intensity, more urban public service facilities, higher density of urban road network, mainly small-scale blocks, large number of urban primary schools built for a long time and small scale and the surrounding areas. Outside the Second Ring Road, there are mainly new urban areas with low road network density, mainly in super large and street areas. Most of the primary schools in this area are newly-built primary schools along with the development of the new urban area. The surrounding land is mainly new gated communities.

The study selected two primary schools in different urban areas of Harbin as the research objects (Figure 1). The choice is based on the school's geographic location (city center or fringe area), density, green diversity and representativeness of the built environment. Fuhua Primary School is an urban primary school in the old city, and Fuhua Science and Technology Park Primary School is an primary school for new commercial housing in the new urban area. Most students live in the school districts defined by the "nearest enrollment" policy, and a few students go to school across districts
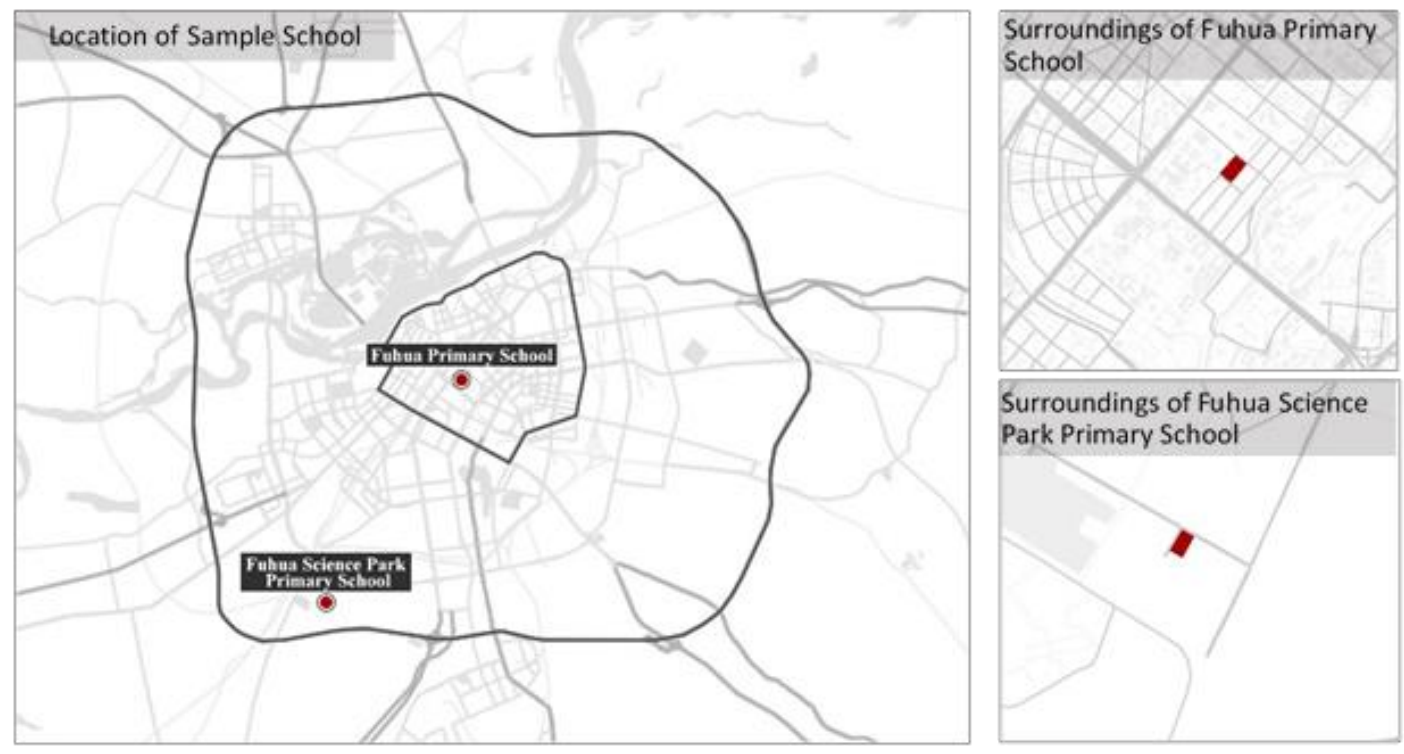

Figure 1. Location of sample primary school. Source: Author.

\subsection{Data Collection}

The research adopted questionnaire survey to collect data. The subjects of the survey are the parents of primary school students aged 6-12. The goal of research is to collect data on children's behavioural characteristics, built environment perception and personal information from the perspective of parents. Although it may be more direct to use children as the survey object, the cognition and expression of young children are not enough to complete the survey. In addition, similar studies abroad also use the method of investigating parents, and the credibility is recognized [21]. In terms of school travel behaviour characteristics, the pupils' mode, time and companionship of school travel were recorded. As for cognition of the built environment, the Likert five-level scale was used to collect parents' perceptions of children's commuting safety satisfaction evaluation of indicators including business vitality, facility quality, neighbourhood relations, environmental recognizability, motor vehicle flow, etc. The survey's questions are all active expressions that affect the safety of primary school students on the 
environmental factors (for example: Are the commercial stores on the school travel path diverse and energetic?). The answer is divided into five levels of "very dissatisfied-less satisfied-moderate-relatively satisfied-satisfied" (corresponding to a score of 1-5). The recorded personal information includes gender, grade, parent age, etc. The questionnaire is distributed in two ways: 1 ) intercepting parents who pick up and drop off children at the entrance of the primary school; 2) deliver the online questionnaire to the parent group of primary school students. The data was collected from November 2019 to January 2020, and a total of 208 valid questionnaires were collected as analysis samples.

\subsection{Participant Characteristics and School Travel Behaviour Characteristics}

$54 \%$ of samples are boys and $46 \%$ are girls. The children are mainly in middle and low grades: $48 \%$ are grade one and two, $38 \%$ are grade three and four, and only $14 \%$ are grade five and six. This may be due to the relatively few parents of senior students. Among the parents who pick up and drop off the children, mothers account for 2/3; ages are concentrated between $31-50$ years old: $6 \%$ of parents are under 30 years old, $60 \%$ are $31-40$ years old, $30 \%$ are $41-50$ years old and $4 \%$ are $51-60$ years old.

School travel refers to urban primary school students traveling to and from school. Primary school family travel includes two levels: the first level is the main body of school travel; the second level is characteristics of school travel (including travel distance, travel time, travel mode, etc.) ${ }^{[20]}$. The study found that out of considerations for safety, including traffic conditions, public security and cold weather, primary school students are mostly transported to and from school by their parents, and the proportion of transport in winter is higher than other three seasons. In terms of travel time, primary school students mainly travel in short distances during school trips, and the travel time increases with school trips. After a certain period of time, they show a significant decline. Ninety percent of primary school students spend less than 30 minutes to go to school. Fuhua Science and Technology Park Primary School, located in the newly-built commercial housing complex in the new urban area, has a higher percentage of long-distance schooling than the Fuhua Primary School in the old city. In terms of travel mode, primary school students mainly go to school by walking, and the proportion of primary school students in gated communities is higher than that in open blocks. For different modes of transportation, families have different demands. Families traveling on foot have higher requirements for safety and continuity of walking space, and hope that certain activity nodes can be set up on the way to school; families traveling by private cars show demand for parking space.

Primary school students' school travel behaviour is affected by various factors such as commuting environment, place, time, etc. Their physical and psychological characteristics and age are the main factors affecting their school travel behaviour. On the way of primary school students, their behaviours generally show the characteristics of randomness, clustering and obstruction. Specific activities mainly include walking, crossing, staying, playing, shopping and waiting. Among them, walking and crossing occur most frequently. Activities such as staying, playing, and shopping mainly occur after school in the afternoon. And due to the lack of open space in the community, these activities mostly occur on the sidewalk. Analyzing the psychological demands of primary school students, it is found that the space that primary school students like mainly has the characteristics of being able to meet shopping needs, having good landscape conditions and being able to provide sufficient space for activities..

\section{Assessment of Commuting Environment}

\subsection{Evaluation System Construction}

The current research on children's school travel is mainly based on the degree of observation of the built environment, and lacks the measurement of children's subjective perception dimensions. But for 
children, the perception of the environment, especially the perception of safety and health, has a more significant impact on their school travel behaviour than adults ${ }^{[1]}$. Therefore, this paper is carried out from the perspective of children's subjective perception. With reference to the widely used 5D model in the International Classification of Built Environment Material Elements, combining with the above-mentioned research and the summary analysis of field investigations, this paper hackles the community-level built environment factors that affect primary school travel from three aspects: environment design, social management, and road traffic (Table 1$)$.

Table 1. Indicator system

\begin{tabular}{|c|c|c|c|}
\hline Target Layer A & Criterion layer B & Classification layer $\mathrm{C}$ & Index Layer D \\
\hline \multirow{25}{*}{$\begin{array}{l}\text { Influencing factors of } \\
\text { the pupils' commuting } \\
\text { environment }\end{array}$} & \multirow{8}{*}{ Environment design } & \multirow{3}{*}{ Pedestrian environment } & Street thermal environment \\
\hline & & & Street interface color \\
\hline & & & Street view \\
\hline & & \multirow{5}{*}{ Activity environment } & Environmental occlusion \\
\hline & & & Plant safety \\
\hline & & & Environment recognizability \\
\hline & & & Spatial hierarchy \\
\hline & & & Iconic node \\
\hline & \multirow{8}{*}{ Social management } & \multirow{5}{*}{ Environment management } & Facility maintenance \\
\hline & & & Road occupation management \\
\hline & & & Business dynamics \\
\hline & & & Road cleanliness \\
\hline & & & Facility quality \\
\hline & & \multirow{3}{*}{ Social supervision } & Monitoring equipment \\
\hline & & & Neighborhood relations \\
\hline & & & Street eye \\
\hline & \multirow{9}{*}{ Road traffic } & \multirow{4}{*}{ Road design } & Motor vehicle flow \\
\hline & & & Human flow \\
\hline & & & Motor vehicle speed \\
\hline & & & Sidewalk width \\
\hline & & \multirow{5}{*}{ Traffic facilities } & Security fence \\
\hline & & & Crossing facilities \\
\hline & & & Lighting facilities \\
\hline & & & Signal facilities \\
\hline & & & Anti-slip paving \\
\hline
\end{tabular}

\subsection{Assessment Method and Results}

\subsubsection{Importance Assessment}

Use the Analytic Hierarchy Process(AHP) to evaluate the importance of influencing factors. Consult the opinions of 10 experts, make comparative judgments on the importance of various indicators, and establish a judgment matrix. The judgment rule is that the expert compares the importance of every two factors of the same level ( $i$ and $j$ ) and assigns a score (Table 2), determines the pairwise evaluation matrix, and solves the maximum eigenvalue of each matrix and the corresponding eigenvector, carry out normalization processing and consistency test, and finally get the index system weight (Figure 2).

Table 2. Expert marking table

\begin{tabular}{|c|c|}
\hline Scale $\mathrm{a}^{\mathrm{ij}}$ & Implication \\
\hline 1 & $\mathrm{i}$ is as important as $\mathrm{j}$ \\
\hline 3 & $\mathrm{i}$ is slightly more important than $\mathrm{j}$ \\
\hline 5 & $\mathrm{i}$ is more important than $\mathrm{j}$ \\
\hline 7 & $\mathrm{i}$ is particularly more important than $\mathrm{j}$ \\
\hline 9 & $\mathrm{i}$ is absolutely more important than $\mathrm{j}$ \\
\hline $2,4,6,8$ & The scale of the state between the two judgments \\
\hline Reciprocal & When $\mathrm{j}$ is compared to $\mathrm{i}$, the result is $1 / \mathrm{a}^{\mathrm{ij}}$ \\
\hline
\end{tabular}

$\mathrm{i}$ is the vertical index, $\mathrm{j}$ is the horizontal index 


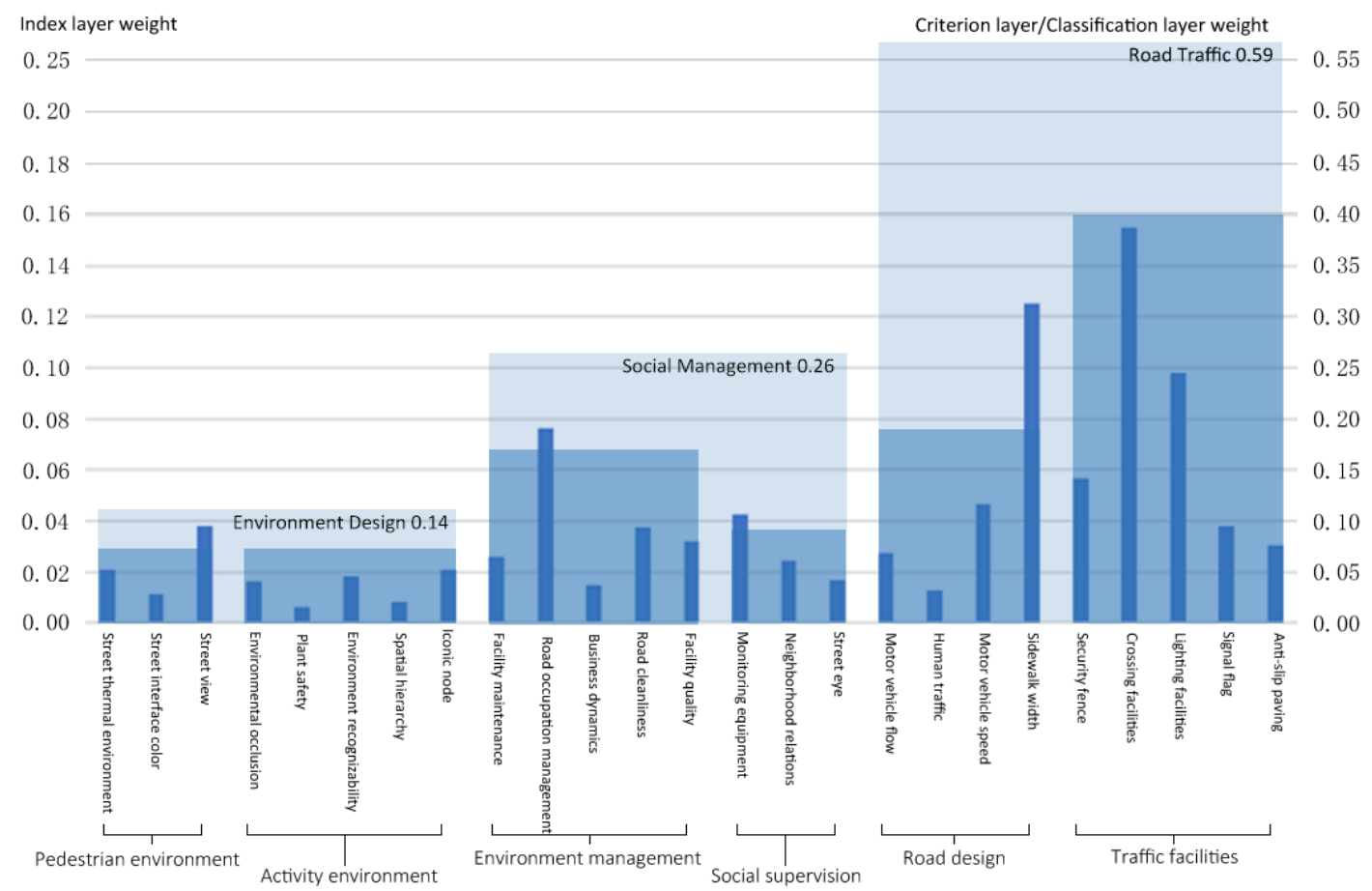

Figure 2. Importance evaluation score. Source:Author.

Among the three first-level indicators that affect the environmental safety of school travel, the order of importance is road traffic>social management>environment design in which the importance of road traffic is prominent and traffic facilities play a major role. Among the specific influencing factors, the most weighted items are crossing facilities, sidewalk width, lighting facilities and road occupation management. This result is consistent with the findings of existing research. Wang Xia found that traffic infrastructure, including sidewalks, walking paths, and pedestrian crossing facilities, are the main means to promote active traffic ${ }^{[20]}$. Fulton et al. found that the proportion of walking to school is higher in the built environment with high pavement integrity ${ }^{[22]}$. Ahlport et al. found that excessive driving speed and the lack of pedestrian traffic lights and other facilities will cause parents to worry about the safety of children walking and cycling to school ${ }^{[23]}$.

\subsubsection{Performance Assessment}

In the evaluation process, each indicator condition is divided into five levels: very dissatisfied, less dissatisfied, fair, satisfied, and very satisfied, and the corresponding evaluation score is 1-5. Through the questionnaire survey, the satisfaction evaluation of pupils' parents is obtained. And counting and assigning the questionnaires, we obtain the satisfaction degree of the school environment safety around gated communities and open blocks (Figure 3). The overall school travel safety satisfaction of the two types of communities are 3.59 and 3.07 respectively, which shows that parents are basically satisfied with the current commuting environment. The distribution of parent satisfaction among the three types of factors is relatively even. The indicators that parents are dissatisfied with mainly include street thermal environment, road occupation management, and anti-slip paving, etc., which are closely related to the harsh weather in winter. The satisfaction level of gated communities is slightly higher than that of open blocks, and there is a large gap in the number of landmark nodes and the flow of motor vehicles. This may be related to the more marginal location of gated communities and the relatively independent open space system. In terms of neighbourhood relations and street thermal environment, the degree of satisfaction of open blocks is higher. Open blocks are mostly unit-employed residences, which have a 
better neighbourhood foundation, and the enclosed building layout has a better windproof effect than row-type.

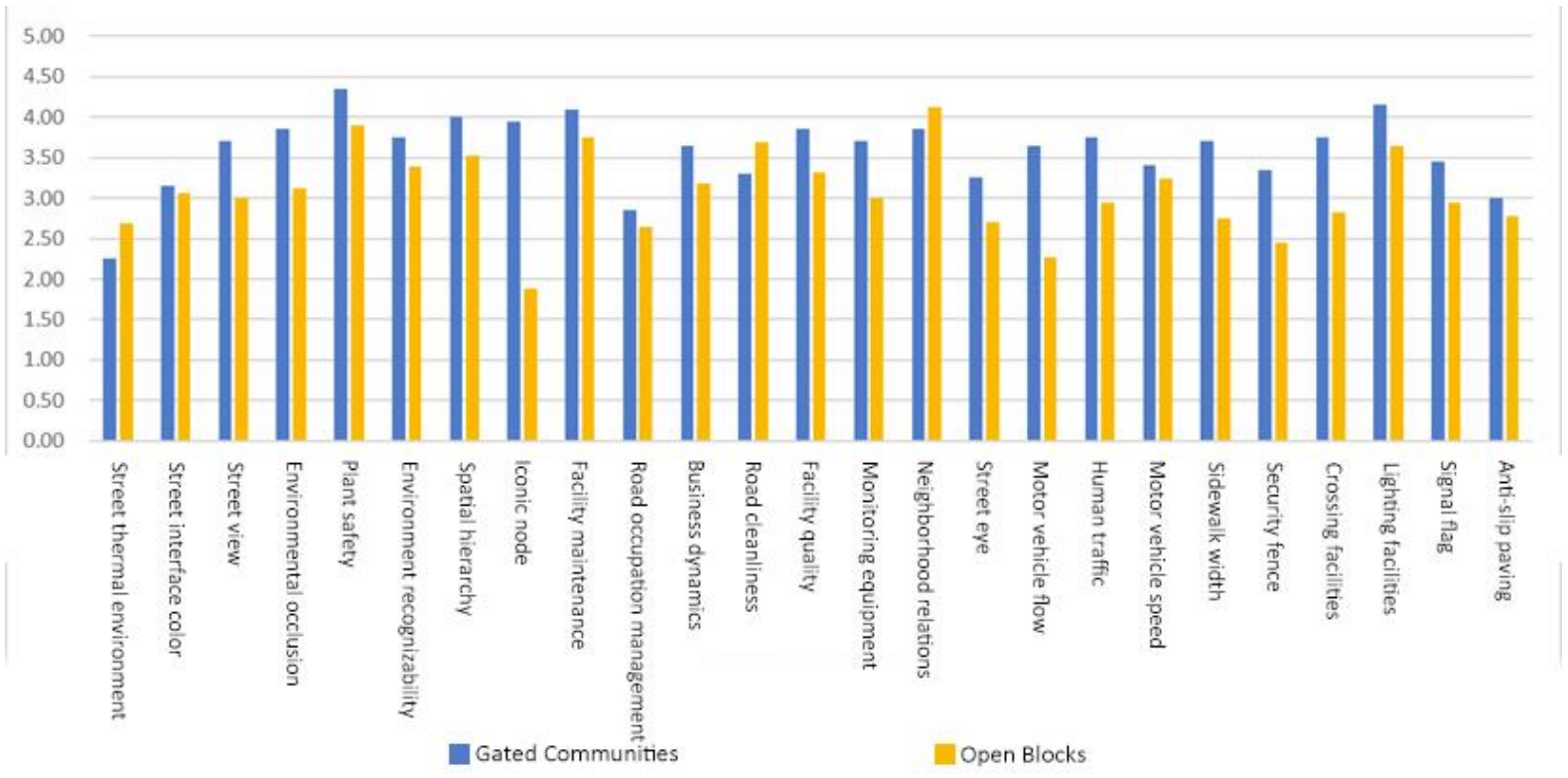

Figure 3. Performance evaluation score. Source:Author.

\subsubsection{Comprehensive Assessment}

Draw IPA quadrant diagrams for open blocks and gated communities. The $X$-axis represents the satisfaction evaluation of index, the Y-axis represents the index weight, and the intersection of the average satisfaction value and the average importance value is used as the origin. The indicator data is in the quadrant. The quadrants from one to four are A superiority zone, B repairing zone, C improving zone, D maintenance zone (Figure 4).

In terms of open blocks, the indicators in A superiority zone and D maintenance zone have high index satisfaction, which are mainly subordinate to environment design and social management, and should continue to be strengthened on the basis of maintaining the status quo. The indicators in the $B$ repairing zone are of high importance but low satisfaction. They are the main factors affecting primary school students' active school travel, need to be improved preferentially. These indicators are mainly road traffic indicators, including crossing facilities, sidewalk management, safety fences, signal facilities, etc. The indicators in $\mathrm{C}$ improving zone have both low importance and low satisfaction. They are mainly belong to environment design, including iconic nodes, street thermal environment, interface colors, etc. Although it affects the commuting experience, it does not cause too much impact on safety. It can lag behind the indicator in Zone $B$ and give priority to solving major contradictions. The indicators of gated communities are concentrated in zones $A$ and $D$ with high satisfaction ratings. The environment design has outstanding performance, which shows that orderly environment can bring a certain sense of security to parents. The elements that need to be improved urgently are basically the same as open blocks. Motor vehicle speed and road cleanliness require additional attention. Mcmillan et al. found that speed greater than $30 \mathrm{~km} / \mathrm{h}$ and unsafe neighborhood environment will reduce the proportion of children walking ${ }^{[24]}$. Wilson's Broken Windows theory suggests that orderly environment can reduce crime ${ }^{[25]}$. 

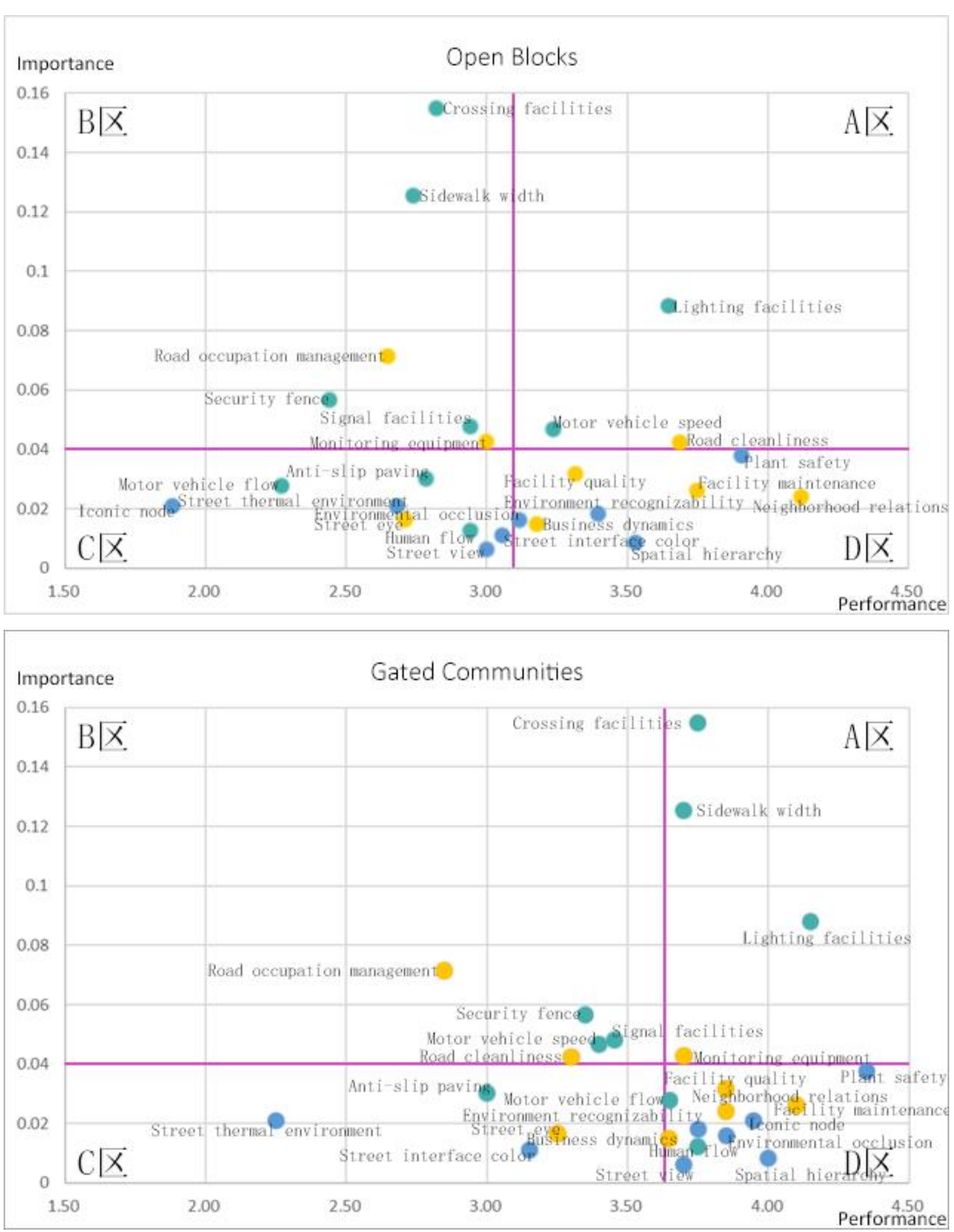

Figure 4. Comprehensive Assessment. Source: Author. 


\section{Strategy}

\subsection{Plan the time sequence of renovation reasonably}

In the process of community micro-update, there are differences in the status quo and limited reconstruction funds and capabilities. Therefore, targeted micro-update construction timing planning should be carried out for different aging degrees and different types of communities. Understand the issues that users are most concerned about, consider the needs of vulnerable groups such as the elderly and children, and resolve the main contradictions that most affect the quality of life of residents. This requires that in the planning and construction, the order of projects should be rationally arranged according to the current conditions of different communities, and based on the above-mentioned satisfaction evaluation results and the quadrant diagram, the proposed development sequence diagram of the two communities under the background of improving the safety of primary school students (figure 5) According to the actual situation, it is divided into three phases: priority renovation, key construction and follow-up.

\begin{tabular}{|c|c|c|c|}
\hline & Priority Renovation & Key Construction & Follow up \\
\hline $\begin{array}{l}0 \\
\text { D } \\
\end{array}$ & 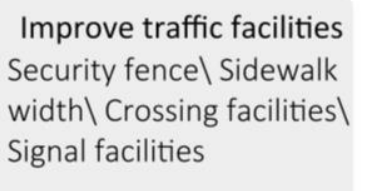 & $\begin{array}{l}\text { Upgrade road design } \\
\text { Motor vehicle speed } \backslash \\
\text { Motor vehicle flow } \backslash \\
\text { Human flow facilities }\end{array}$ & 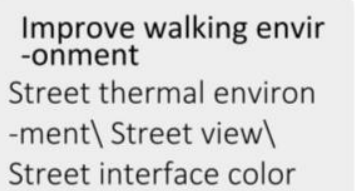 \\
\hline $\begin{array}{l}\frac{0}{0} \\
\frac{n}{n}\end{array}$ & $\begin{array}{l}\text { Enhance road manage } \\
\text {-ment } \\
\text { Road occupation } \\
\text { management\Monitor } \\
\text {-ing equipment }\end{array}$ & $\begin{array}{l}\text { Enhance environment } \\
\text { management } \\
\text { Road cleanliness }\end{array}$ & $\begin{array}{l}\text { Improve activity envir } \\
\text {-onment } \\
\text { Iconic node\Environment } \\
\text { occlusion }\end{array}$ \\
\hline $\begin{array}{l}0 \\
\stackrel{2}{+} \\
D \\
2 \\
0 \\
0\end{array}$ & $\begin{array}{l}\text { Enhance environment } \\
\text { management } \\
\text { Road occupation } \\
\text { management } \backslash \text { Road } \\
\text { cleanliness }\end{array}$ & $\begin{array}{l}\text { Improve traffic facilities } \\
\text { Sidewalk width } \backslash \text { Crossing } \\
\text { facilities } \backslash \text { Lighting facilities }\end{array}$ & $\begin{array}{l}\text { Improve walking envir } \\
\text {-onment } \\
\text { Street thermal environ } \\
\text {-ment \Street interface } \\
\text { color }\end{array}$ \\
\hline 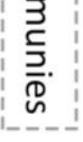 & $\begin{array}{l}\text { Improve traffic facilities } \\
\text { Security fence \Signal } \\
\text { facilities }\end{array}$ & $\begin{array}{l}\text { Strengthen social super } \\
\text {-vision } \\
\text { Monitoring equipment } \\
\text { Street eye }\end{array}$ & $\begin{array}{l}\text { Upgrade road design } \\
\text { Anti-slip paving } \backslash \text { Motor } \\
\text { vehicle flow }\end{array}$ \\
\hline
\end{tabular}

Figure 5. Time Sequence of Renovation. Source: Author.

\subsection{Improve traffic facilities}

Road traffic indicators play an important role in the pupils' commuting safety. Environmental intervention is one of the most effective methods to control traffic injuries ${ }^{[26]}$. In terms of vehicle facilities, Improvement measures include the installation of traffic signals and pedestrian crossing timers, setting up fully paved intersections, reducing the turning radius of intersections, and laying speed bumps. Intersection is a high incidence of pedestrian, bicycle, and motor vehicle crashes ${ }^{[27]}$. Zegeer et al. found that special phase lights for pedestrian crossings can reduce pedestrian-vehicle conflicts by about $50 \%{ }^{[28]}$. Prevedouros et al. have shown that crosswalks can remind drivers of pedestrians' crossing behavior, reducing vehicle speed by $25 \%{ }^{[29]}$. Tester et al. found that the speed bump project is related to the reduction of the probability of children encountering motor vehicle collision accidents ${ }^{\left[{ }^{30} \text {. Pedestrian }\right.}$ function facilities include widening sidewalks on the sunny side, splicing sidewalk spacing, and using 
brightly colored crosswalk colors. In Boarnet's evaluation of the Safe Routes to School program (SRTS) for 10 primary schools in California, it is shown that sidewalk spacing splicing is the most successful intervention ${ }^{[11]}$. Because of the wet and slippery road, children slip and fall more frequently in winter. Therefore, laying of non-slip paving in winter city is also of great significance to improving the safety of pupils' commuting environment.

\subsection{Enhance environment management}

It can be seen from the quadrant chart that in addition to transportation facilities, environmental management indicators also need to be improved, including strengthening management of road occupations, adding monitoring facilities, and keeping roads clean. Scholars have found that in the built environment with higher pavement integrity and smoother traffic, the proportion of children walking to school is higher ${ }^{[22]}$. Sufficient and effective monitoring facilities can deter bad actors and reduce the crime rate in the community, so as to protect children's defense safety. The broken window theory points out that orderly built environment has a lower crime rate than an environment that is messy and full of graffiti ${ }^{25]}$. In addition, snow and ice on the road will reduce the braking efficiency of motor vehicles. Clearing snow in time will help ensure driving safety, reduce human-vehicle conflicts and reduce the probability of children slipping.

\section{Conclusion}

Based on the perspective of pupils' commuting safety, this paper takes two representative primary schools in Harbin as an example. Through questionnaires and interviews with parents, this paper organizes and analyses the basic characteristics of primary school travel and the real views of the primary school students and their parents on the current school environment. Overlapping it with expert rights, we find the points of correspondence and conflicts between the actual wishes of primary school students' parents and the current commuting environment.

The result shows that pupils' school travel has the characteristics of parent accompany, time and space distance increasing, and motorization. The traffic problem is the urgent problem to be solved in the construction of a safe school travel road, which should be considered and improved first, such as security fence and crossing facility. Families living in gated communities and those living in open blocks have certain differences in satisfaction with different indicators. The overall satisfaction of gated communities is higher, but neighbourhood relations and street thermal environment still need to be improved. Iconic nodes and traffic flow in open blocks need to be focused. It can be seen that in the process of community renewal, different types of communities should be designed differently. Based on the results, the strategy of rational planning and updating, improving traffic facilities, and enhancing environment management is proposed, in order to provide reference for the next step of the reconstruction of old communities and the construction of open blocks.

The insufficiency of the research is reflected in only considering the impact of built environment factors on pupils' school trave, while ignoring the role of non-built environment factors, such as family attitudes, socio-economic conditions, age, gender, etc. In the future experimental design, non-built environment factors should be taken into consideration and improved.

Funding: National Natural Science Foundation of China-Research on Urban Space Impact Mechanism and Planning Regulation Technology Based on Residents' Cardiovascular Health Effect in Severe Cold Region (51978192).

Acknowledgments: Special thanks are given to my teachers and the reviewers for their valuable comments. Their contribution has indeed improved the work. 


\section{References}

[1] Wang, X. and Jiao, J. (2018) 'A Review of Built Environment Research Based on Children's School Travel Behaviour', Urban Planning International, 62(9), p70-81.

[2] Chillon, P., Ortega, F.B., Ruiz, J.R., Veidebaum, T., Oja, L., Mäestu, J. and Sjöström, M. (2010) 'Active commuting to school in children and adolescents: an opportunity to increase physical activity and fitness', Scandinavian journal of public health, 38(8), pp.873-879.

[3] Lubans, D.R., Boreham, C.A., Kelly, P. and Foster, C.E. (2011) 'The relationship between active travel to school and health-related fitness in children and adolescents: a systematic review', International Journal of Behavioural Nutrition and Physical Activity, 8(1), pp.1-12.

[4] Villa-González, E., Ruiz, J.R. and Chillón, P. (2015) 'Associations between active commuting to school and health-related physical fitness in Spanish school-aged children: a cross-sectional study', International journal of environmental research and public health, 12(9), pp.10362-10373.

[5] Ruiz-Ariza, A., de la Torre-Cruz, M.J., Redecillas-Peiro, M.T. and Martinez-Lopez, E.J. (2015) 'Influence of active commuting on happiness, well-being, psychological distress and body shape in adolescents', Gaceta sanitaria, 29(6), p.454.

[6] Giles-Corti, B., Foster, S., Shilton, T. and Falconer, R. (2010) 'The co-benefits for health of investing in active transportation', New South Wales public health bulletin, 21(6), pp.122-127.

[7] Jiao, J. (2019) 'Promoting Children's Walking and Cycling to School: Enlightenment from Safe Routes to School Program in Euramerican Cities', Shanghai Urban Planning Review, (3), p.16.

[8] Carver, A., Timperio, A., Hesketh, K. and Crawford, D. (2010) 'Are children and adolescents less active if parents restrict their physical activity and active transport due to perceived risk?', Social science \& medicine, 70(11), pp.1799-1805.

[9] Oliver, M., Badland, H., Mavoa, S., Witten, K., Kearns, R., Ellaway, A., Hinckson, E., Mackay, L. and Schluter, P.J. (2014) 'Environmental and socio-demographic associates of children's active transport to school: a cross-sectional investigation from the URBAN Study', International Journal of Behavioural Nutrition and Physical Activity, 11(1), p.70.

[10] Panter, J., Corder, K., Griffin, S.J., Jones, A.P. and van Sluijs, E.M. (2013) 'Individual, socio-cultural and environmental predictors of uptake and maintenance of active commuting in children: longitudinal results from the SPEEDY study', International journal of behavioural nutrition and physical activity, 10(1), p.83.

[11] Ekawati, S.A. (2015) 'Children-Friendly streets as urban playgrounds', Procedia-Social and Behavioural Sciences, 179, pp.94-108.

[12] Wu, F.W. and Chen, M.Y. (2020) 'The Evaluation and Improvement Strategy of the Way to Primary School from the Perspective of Children', Urban Development Studies ,27(07), pp.20-27.

[13] Wang, T. (2006). Research on the District Space in Ancient Cities Causing Children Communication Behaviours - -An Example of JingYing District in Taiyuan (Master's thesis, Huazhong University of Science \& Technology).

[14] D’Haese, S., Vanwolleghem, G., Hinckson, E., De Bourdeaudhuij, I., Deforche, B., Van Dyck, D. and Cardon, G. (2015) 'Cross-continental comparison of the association between the physical environment and active transportation in children: a systematic review', International journal of behavioural nutrition and physical activity, 12(1), p.145. 
[15] Klesges, R.C., Eck, L.H., Hanson, C.L., Haddock, C.K. and Klesges, L.M. (1990) 'Effects of obesity, social interactions, and physical environment on physical activity in preschoolers', Health psychology, 9(4), p.435.

[16] McMillan, T.E. (2005) 'Urban form and a child's trip to school: the current literature and a framework for future research', Journal of planning literature, 19(4), pp.440-456.

[17] Kerr, J., Rosenberg, D., Sallis, J.F., Saelens, B.E., Frank, L.D. and Conway, T.L. (2006) 'Active commuting to school: associations with environment and parental concerns', Medicine \& Science in Sports \& Exercise, 38(4), pp.787-793.

[18] Cervero, R. (1996) 'Mixed land-uses and commuting: Evidence from the American Housing Survey', Transportation Research Part A: Policy and Practice, 30(5), pp.361-377.

[19] Yang, S., Gao, X. and Li, Z. (2017) 'A Research on the Relationship between the Path on Which Kids Go after School and the Space Structure of Community', Urban Design, (4), pp.62-69.

[20] Wang, X. and Chen, X.J. (2018) 'Spatial-Temporal Characteristics and Constraint of Primary School Commuting in Xi'an City', City Planning Review, (11), p.19.

[21] Tappe, K.A., Glanz, K., Sallis, J.F., Zhou, C. and Saelens, B.E. (2013) 'Children's physical activity and parents' perception of the neighborhood environment: neighborhood impact on kids study', International journal of behavioural nutrition and physical activity, 10(1), p.39.

[22] Fulton, J.E., Shisler, J.L., Yore, M.M. and Caspersen, C.J. (2005) 'Active transportation to school: findings from a national survey', Research quarterly for exercise and sport, 76(3), pp.352-357.

[23] Ahlport, K.N., Linnan, L., Vaughn, A., Evenson, K.R. and Ward, D.S. (2008) 'Barriers to and facilitators of walking and bicycling to school: formative results from the non-motorized travel study', Health Education \& Behaviour, 35(2), pp.221-244.

[24] McMillan, T.E. (2007) 'The relative influence of urban form on a child's travel mode to school', Transportation Research Part A: Policy and Practice, 41(1), pp.69-79.

[25] Wilson, J.Q. and Kelling, G.L. (2003). 'Broken Windows: The police and neighborhood safety', Criminological perspectives: essential readings, 400.

[26] Haddon Jr, W. (1980) 'Advances in the epidemiology of injuries as a basis for public policy', Public health reports, 95(5), p.411.

[27] Dumbaugh, E., Li, W. and Joh, K. (2013) 'The built environment and the incidence of pedestrian and cyclist crashes', Urban Design International, 18(3), pp.217-228.

[28] Zegeer, C.V., Opiela, K.S. and Cynecki, M.J. (1985) 'Pedestrian Signalization Alternatives', Final Report (No. FHWA-RD-83-102).

[29] Prevedouros, P.D. (2001). August. Evaluation of in-pavement flashing lights on a six-lane arterial pedestrian crossing. In ITE 2001 Annual Meeting, ITE.

[30] Tester, J.M., Rutherford, G.W., Wald, Z. and Rutherford, M.W. (2004) 'A matched case-control study evaluating the effectiveness of speed humps in reducing child pedestrian injuries', American journal of public health, 94(4), pp.646-650.

[31] Orenstein, M.R., Gutierrez, N., Rice, T.M., Cooper, J.F. and Ragland, D.R. (2007). Safe Routes to School: Safety \& Mobility Analysis: Report to the California Legislature. 